\title{
Exploring Gender Gaps: How Nigerian Micro Business Owners Use Mobile Apps for Business
}

\author{
Adebowale Owoseni ${ }^{10000-0001-8360-3197]}$, Kutoma Wakunuma ${ }^{10000-0002-8236-3221]}$, Ade- \\ damola Tolani 2[0000-0003-1429-0902] and Hossana Twinomurinzi 2[0000-0002-9811-3358] \\ ${ }^{1}$ Centre for Computing and Social Responsibility, School of Computer Science and Informat- \\ ics, De Montfort University, Leicester LE19BH, UK \\ ${ }^{2}$ School of Computing, University of South Africa, Pretoria, SA \\ adebowale. owosenidadmu. ac.uk
}

\begin{abstract}
.
This study examined how men and women who own micro businesses in Lagos, Nigeria, use mobile apps for business. The paper analyses the findings from Amartya Sen's capability approach viewpoint. The two key findings suggest that women micro business owners make more use of mobile apps compared to men, and that they tend to exit micro businesses as they grow older indicating a possible influence of patriarchy in African contexts. Specifically, women seized opportunities presented by mobile apps to acquire capabilities to function; and they adapt mobile apps to enhance their wellbeing and freedom despite the restrictions and responsibilities in the patriarchal environments typical of low-income countries. The insignificant gender gap in certain mobile app usages presents new perspectives to debates on gender (economic) gaps, inequality, women empowerment, and technology uptake in low-income country contexts.
\end{abstract}

Keywords: Mobile apps usage, gender gap, micro-business owners, microbusinesses, capability approach.

\section{Introduction}

Inequality in its various forms magnifies challenges [1] such as unemployment, poverty, and hunger. In the context of micro-businesses (MBs), inequality could manifest in form of economic empowerment of business owners [2] for both men and women. It is therefore important to understand how gender inequality affects micro business owners (MBOs), particularly as MBs are the foundation of any economy $[3,4]$ especially in developing countries.

Usually, economic challenges in MBs are addressed by encouraging strategic use of Information and Communication Technology (ICT) [5-6]. However, the adoption and usage of ICT could create unintended inequality across gender, particularly in developing African country contexts, which are often patriarchal in nature [2,7]. Hence the need to understand gender perspectives of ICT usage in MBs. Arguably, emerging ICTs such as mobile apps are positively impacting how MBs are conducted [9]. Nevertheless, few 
works of literature have considered the gender aspects when it comes to the usage of mobile apps and how it could influence gender gaps in Africa.

Considering Nigeria as a case example for the study presented in this paper due to its low-income and developing country status, $97.8 \%$ of MBs are not registered [10,11], suggesting that they constitute the informal business sector. It is argued that more than half of the informal sector business owners are women [10]. This also aligns with the fact that women constitute $49 \%$ of 200.96 million Nigerians. As such, understanding how men and women use mobile apps for MBs in a patriarchal, and significant women populated environment could inform the discourse on gender (economic) gaps, jobs creation, poverty reduction and economic growth $[2,12,13]$. Thus, this exploratory study offers an insight into how mobile app usage by MBOs reflect gender gaps in Lagos, Nigeria.

The remainder of this article presents the theoretical framework, research objectives, underlying literature, research approach, results, discussions, and implications of findings.

\section{Theoretical framework: capability approach}

The extent of freedom enjoyed by people in a community, arguably informs their perception of equality $[14,15]$. Amartya Sen defines freedom as not only a measure of an individual's possession of the means to achieve such as money, cars, and houses, but also includes their functioning - the ability to become who they want to be, by doing what they like to do [16-18].

Arguably, mobile apps are widely accepted ICTs in low-income countries $[9,12]$. Mobile apps tend to enhance individual's perception of freedom when adapted to solve contextual problems in fast-evolving environments [12], particularly as it applies to managing MBs. For example, knowledge about mobile apps could enhance the ability to do more business, doing more business could provide opportunities to earn more income and achieve some personal goals, which could result in improved self-esteem. In low-income countries, it is perceived that women make limited use of technology such as mobile apps [19], this situation influences women functioning, and potentially creates gender gaps [15,20]. Understanding the mobile app usage capabilities of MBOs along gender differences in this regard could reveal the dimension of inequality and possible approaches to close the gap.

Although, other theoretical viewpoints such as social balance theory, and digital divide framework, appear relevant to ICT and gender discourse, the capability approach is suitable and applicable to explore human development, gender gaps and social practices $[15,16]$ on three grounds: First, the capability approach is a normative theory that considers individual perspectives; secondly, it recognises peoples functioning in formal and informal situations, and thirdly, it appreciates the diversity of individuals in a community while developing their individual capabilities [14,15]. Within the context of this study, the capability approach was used to illustrate the freedom that comes from 
the use of mobile apps, particularly for women. Moreover, attention is drawn to unrealized freedoms from using mobile apps between gender and the contrast between men and women with their use of mobile apps for micro businesses.

\section{Research objectives}

This research sought to explore how men and women who own micro-business in Lagos Nigeria use mobile apps for business. Specifically, the study seeks to answer the following research question: How does mobile app usage by microbusiness owners reflect gender and freedom gaps in Lagos, Nigeria?

\section{$4 \quad$ Review of literature}

This section provides the underlying literature for this study in a low-income country context, it considers micro-businesses as economic development factor, mobile apps as ICT for enhancing micro-businesses, and the influence of gender in mobile app usage in micro-businesses.

\subsection{Micro businesses and economic development}

Microbusinesses are autonomous business enterprises managed by owners, or co-owners in a personalized and mostly unstructured way [21-23]. The Nigerian Bank of Industry (BOI) defined micro-businesses as a business entity with a maximum of $10 \mathrm{em}-$ ployees, 5-million-naira total asset and 20-million-naira annual turnover [22]. MBs create economic balance because it creates jobs, prompt innovation and reduces poverty [3-5]. MBs exist across all sectors of the Nigerian economy either as artisans or "whitecollar" consultants, thus the importance of MBs.

It is challenging to know the exact number of MBs in Nigeria because a significant number of MBs do not exist on any government register. Nevertheless, the Small and Medium Enterprises Development Agency of Nigeria (SMEDAN) suggests that approximately 74 million MBs exists in Nigeria, and the MBs engaged more than $85 \%$ of total labor and contributing more than 50\% to the GDP [21,22]. Notwithstanding, the contributions of MBs to the economy, the MB are overwhelmed with challenges such as infrastructural shortfalls, scarce capital, derisory market research, multiple taxation, and poor management (as exhibited in lack of focus, succession plan, proper bookkeeping, and business strategy, etc) [4,5]. Other challenges include the emergence of new technologies that could be disruptive [24]. 


\subsection{Mobile apps as ICT in micro-businesses}

The nature of MBs as entities with limited resources restricts ICT options to drive business [24]. Although MBs have much flexibility in adapting to change, they also carry the risk of extinction due to emerging technologies [25]. For example, the sale of airtime vouchers was a lucrative business two decades ago when mobile telephony $(2 \mathrm{G})$ was new in Nigeria. In recent times, the sale of airtime vouchers as a business is no longer needed because airtime could be purchased directly from Telco via Unstructured Supplementary Service Data (USSD) and mobile banking apps. This disruption is applicable to emergence Uber and extinction of cabdrivers.

Mobile apps are software installed on smartphones, mobile apps interact with the internet and the smartphone hardware like camera, fingerprint scanners and microphones to provide unique capabilities [26-28]. The adoption of mobile apps as a form of ICT by micro-business could enhance the management and the efficiency of business activities. Mobile apps allow users to work remotely, mobile apps defile the odds of working within a structured business hour, provides access to virtual (borderless) markets and reduces the risk of data loss when connected to cloud data storage infrastructure. The usage of mobile apps for business by MBs is cost-effective as the sunk cost is relatively negligible or bearable. Mobile apps used by MBOs in Lagos include social media apps, productivity apps, transport apps and payment apps [29] as illustrated in Figure 1. Ownership and management of MBs in Lagos cuts across male and female gender, which means both men and women are using apps for business.

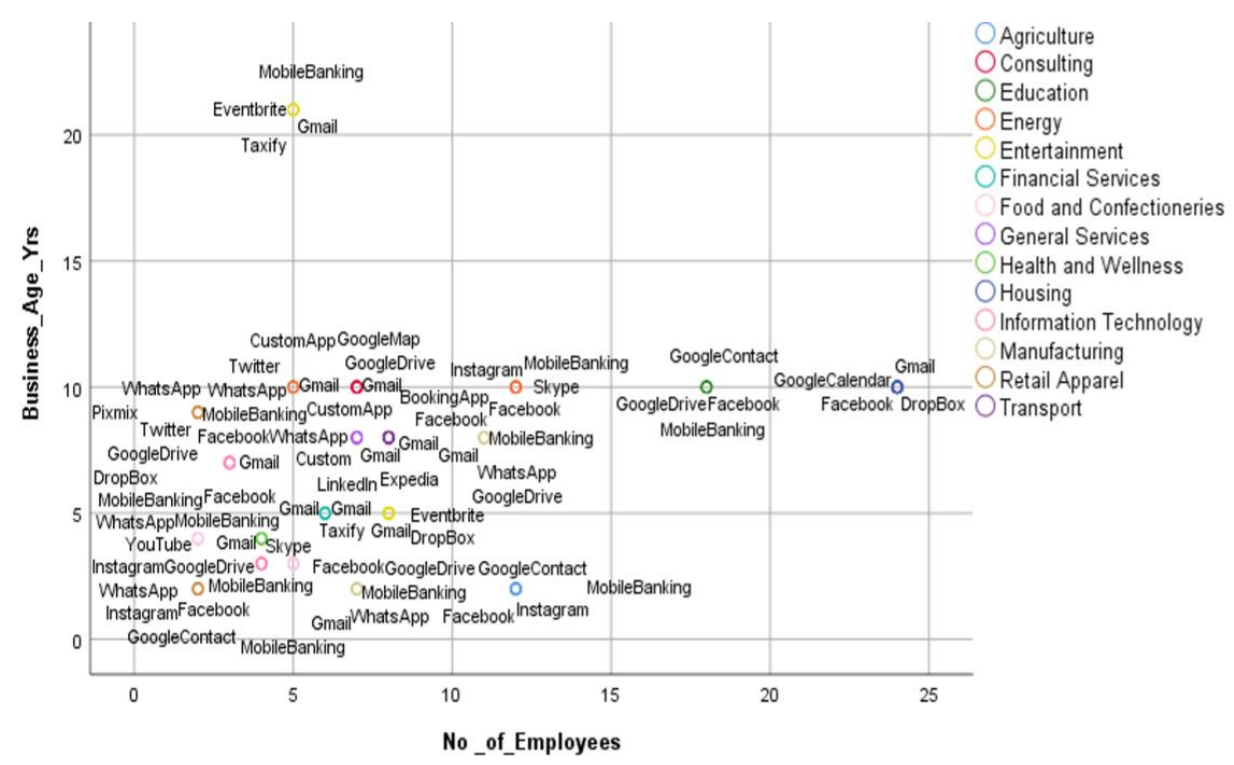

Fig. 1: Mobile apps used by MBOs in Lagos, Nigeria (Source [29]) 


\subsection{Gender and mobile apps adoption in micro-businesses}

Previous studies on gender and micro-businesses had broader perspectives of gender, businesses, and ICTs. For example, Weber \& Geneste [30] focused on the understanding of the perception of business success by men and women. Sharafizad [31] investigated the uptake of ICTs by women who run small businesses. The outcome of the qualitative research affirms knowledge progressions from static webpages to dynamic online transactions, which lays groundwork for examining how women use other ICTs like mobile apps.

The women MBOs perceivably need to combine MB management with family demands like child-raising, home management and other tasks placed by African culture $[2,7]$. The women MBOs would like to work remotely from home or transit, access virtual and borderless markets, and reduce the risk of data loss at relatively low cost. The adoption of mobile apps seems to meet these peculiar needs of women MBOs and perhaps responsible for increasing participation of women in micro-business [32]. There is limited literature with empirical reference as to how women MBOs use mobile apps compared to their male counterparts in low income country context. This exploratory study investigated how mobile app usage by microbusiness owners reflect gender gaps in Lagos, Nigeria.

\section{$5 \quad$ Research approach}

\subsection{The study area}

The research was conducted in Lagos, Nigeria. Geographically, Lagos is the smallest state in Nigeria, nonetheless, it has the highest population density of 23 million people occupying $3577 \mathrm{~km}^{2}$ [33]. Approximately $30 \%$ of Nigeria's economic activities originate from Lagos [34] which, represents $60 \%$ of Nigeria's industrial and commercial activities. Lagos economy is diversified, unlike the larger Nigerian economy which depends severely on proceeds from the oil and gas industry. Lagos generates the highest internal revenue of all states in Nigeria. Thus, Lagos is financially viable and economically stable [34].

\subsection{Data collection}

Using non-probability convenience sampling, the study administered face-to-face questionnaires to 2,500 MBOs in Lagos. To improve participant's responses and reduce data collection errors, 15 field officers were involved in the data collection activities that lasted for 4 weeks. The officers visited MBOs at their business locations and administered the questionnaires which they input in google forms. Apart from questions that retrieved MBOs' demographic details, respondents provided 5-point Likert-scaled responses to 15 questions that elicited feedback for mobile apps usage construct (see table 1). With Likert scale measurement, data output could be subjected to a wider range of 
quantitative analyses [35]. 1159 responses were analyzable. The data collection had ethical approval from statutory University ethical committees.

\subsection{Data evaluation}

The study examined the demographic data of MBOs before focusing on the influence on mobile app usage. The mobile app usage construct is measured along 15 predefined measured variables, while gender gap, and freedom are social constructs within the Nigerian context. The study used descriptive statistics to evaluate the 1,159 5-likert-scale responses. The statistical output includes response counts, mean, standard deviations, variance, kurtosis, skewness. weighted average, and percentage average, all grouped across men and women gender. The responses had Kurtosis and Skewness within an acceptable range of -2 to +2 [35], with very close variances between men and women for 14 out of 15 mobile app usage variables. Minitab 18 was used for the statistical evaluation.

\section{$6 \quad$ Results and discussion}

This section presents the demography of all respondents, and thereafter groups the responses by gender and compares outcomes of men and women MBOs.

\subsection{Exploring gender gaps in demography of micro business owners in Lagos}

The demography consists of 540 women and 619 men respondents which summed up to 1,159 MBOs. Table1 summarized background information of the participants.

Table 1. Demographic analysis of MBOs in Lagos (Source: Field Survey)

\begin{tabular}{llllllll}
\hline \multirow{2}{*}{$\begin{array}{l}\text { Demo- } \\
\text { graphic } \\
\text { Variable }\end{array}$} & Options & \multicolumn{2}{l}{$\begin{array}{l}\text { Frequency Count } \\
\text { (fc) }\end{array}$} & $\begin{array}{l}\text { Frequency } \% \\
\text { (fc \%) }\end{array}$ & \\
\cline { 2 - 8 } & & $\mathrm{W}$ & $M$ & $\mathrm{~T}$ & $\mathrm{~W}$ & $\mathrm{M}$ & $\mathrm{T}$ \\
\hline $\begin{array}{l}\text { Education } \\
\text { Of MBOs }\end{array}$ & $\begin{array}{l}\text { No formal edu- } \\
\text { cation }\end{array}$ & 19 & 24 & 43 & 1.6 & 2.1 & 3.7 \\
\cline { 2 - 8 } & Secondary & 205 & 282 & 487 & 17.7 & 24.3 & 42 \\
\cline { 2 - 8 } & Diploma & 98 & 90 & 188 & 8.5 & 7.8 & 16.2 \\
\cline { 2 - 8 } & Bachelors & 170 & 160 & 330 & 14.7 & 13.8 & 28.5 \\
\cline { 2 - 8 } & Masters & 46 & 59 & 105 & 4.0 & 5.1 & 9.1 \\
\cline { 2 - 8 } & PhD & 2 & 4 & 6 & 0.2 & 0.3 & 0.5 \\
\hline Age of & Total Frequency & 540 & 619 & 1159 & $46.6 \%$ & $53.4 \%$ & $100 \%$ \\
\hline MBOs & $<=20$ years & 97 & 33 & 130 & 8.4 & 2.8 & 11.2 \\
\cline { 2 - 8 } & $21-29$ years & 211 & 201 & 412 & 18.2 & 17.3 & 35.5 \\
\cline { 2 - 8 } & $30-39$ years & 164 & 250 & 414 & 14.2 & 21.6 & 35.7 \\
\cline { 2 - 8 } & $40-49$ years & 43 & 107 & 150 & 3.7 & 9.2 & 12.9 \\
\cline { 2 - 8 } & $50-59$ years & 24 & 21 & 45 & 2.1 & 1.8 & 3.9 \\
\hline
\end{tabular}




\begin{tabular}{llllllll}
\hline & Total Frequency & 540 & 619 & 1159 & $46.6 \%$ & $53.4 \%$ & $100 \%$ \\
\hline \multirow{2}{*}{$\begin{array}{l}\text { Age of } \\
\text { MBs }\end{array}$} & $<=5$ years & 407 & 291 & 698 & 35.1 & 25.1 & 60.2 \\
\cline { 2 - 8 } & 6 -10 years & 88 & 181 & 269 & 7.6 & 15.6 & 23.2 \\
\cline { 2 - 8 } & $11-15$ years & 33 & 74 & 107 & 2.8 & 6.4 & 9.2 \\
\cline { 2 - 8 } & $16-20$ years & 10 & 43 & 53 & 0.9 & 3.7 & 4.6 \\
\cline { 2 - 8 } & $21-25$ years & 2 & 16 & 18 & 0.2 & 1.4 & 1.6 \\
\cline { 2 - 8 } & $>=25$ years & 0 & 14 & 14 & 0.0 & 1.2 & 1.2 \\
\cline { 2 - 7 } & Total Frequency & 540 & 619 & 1159 & $46.6 \%$ & $53.4 \%$ & $100 \%$ \\
\hline
\end{tabular}

$\mathrm{M}=\mathrm{Men}, \mathrm{W}=\mathrm{W}$ omen, $\mathrm{T}=$ Total

Evaluating the demography along the gender construct, the results suggest three gender gap perspectives: 1) Women ownership of MBs at 20 years old is thrice that of men. For instance, 97 female and 33 male respondents were running micro businesses at age 20 years old. 2) A gradual decline in women ownership of MBs as they get older, for example, at 40-49 years, men's ownership is twice that of women. 3) As MBs existed for longer years, fewer women compared to men owned MBs, this is depicted by 181:88 ratio, representing men to women MB ownerships when MBs existed for 6-10 years.

These perspectives corroborate the normative or critical reasoning stance of the capabilities approach [15] with regards to individual's uniqueness to develop capabilities that enhance their freedoms. Women tend to own MBs in their early adulthood because they have less responsibilities for spouse(s) or child(ren), at about 20 years old, women arguably pride themselves in the prestige of being entrepreneurs, earning incomes, and fulfillment of financial independence. However, these freedoms seem to decline in their late thirties and early forties due to increased family demands and cultural pressures on women in a patriarchal community. Remarkably, men who did not own MBs in their early adulthood seemingly developed the capacity to manage MBs for longer years, from their thirties. This could be attributed to what Magidimisha \& Steven [2] termed as different characteristics between men and women. Magidimisha and Steven [2] argued that women's double burden of looking after the home and having to carry out business activities (from home) could impact their capacity or freedom to sustain MBs which is not often the case with men. On the other hand, the men, as they grow older, tend to build more capabilities to meet financial and social demands of their dependents. 


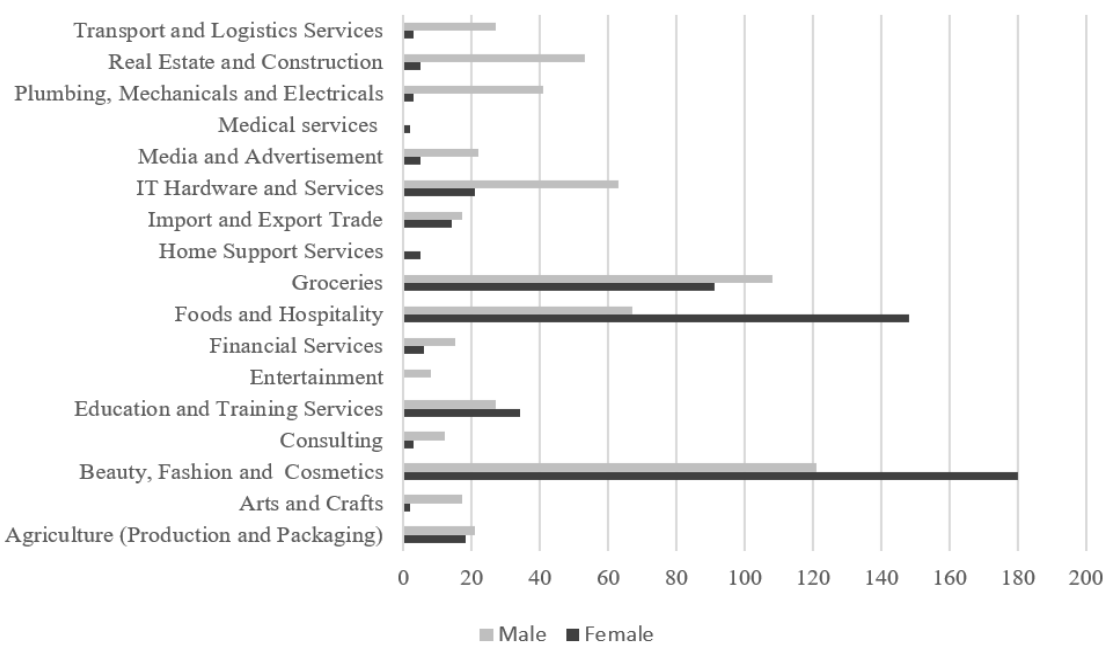

Fig. 2. Distribution of MBOs across business areas (Source: Field Survey).

Furthermore, figure 2 categorizes MBOs along gender and 17 business areas, the figure indicated that women own more MBs than men in all business areas, except groceries. Although, there were high concentration of MBs in business areas that focus on frequent basic needs. For example, $25.97 \%$ were in beauty fashion and cosmetics, $18.55 \%$ in foods and hospitality and $17.17 \%$ in into groceries. Reflecting on these statistics from capability approach standpoint could suggest that women simply turn their socially assigned day to day responsibilities and activities into business ventures, thereby enhancing their functioning and freedom. These responsibilities include preparing food, managing events, dressing well, and looking good.

Based on the demographic evaluation of this study, the concept of gender gaps in the context of MBOs in Lagos Nigeria is not one-sided in favor of men or women. Rather it reveals the complexities, and diversity of individuals while developing their individual capabilities for freedom at different satages of life.

\subsection{Exploring gender gaps in mobile apps usage by micro business owners}

Mobile app usage examined across 15 variables suggests that women MBOs used mobile apps more than men in all variables except virtual meeting and online content creation. Women used mobile apps more than men at providing feedback to customers, generating referrals, managing job orders, advertisement, marketing, online search, payments, funds collections, and e-learning. 


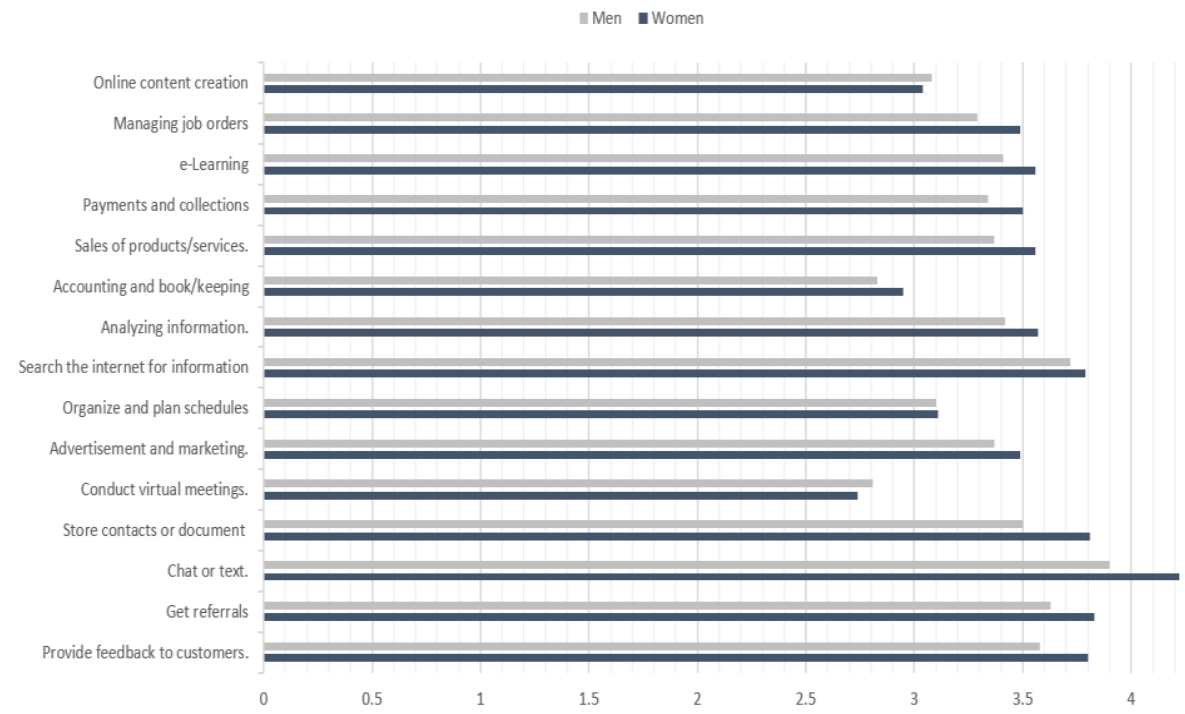

Fig. 3. Distribution of MBOs across 15 mobile app usage constructs (Source: Field Survey).

The inclination of women to operate MBs from home (as home keepers and child minders) could be responsible for increased usage of mobile apps by women, because mobile apps enhances the MBOs capability to work remotely. This is could mean that the gender gap between women and men occasioned by the use of digital technology (such as mobile apps) is reducing. It is more telling when one considers that the total number of women involved in the study were fewer than men but that they used the mobile apps more than their men counterparts. Women like men, can manage their own business. They, like men were not only using mobile apps to chat and text but to do activities like manage business referrals even more than men, manage contacts and documents, manage advertisement and marketing, analyze information, manage sales as well as manage payments and collections.

Therefore, as far as digital technology is concerned in low-income African country contexts (such as Nigeria), particularly in urban areas, women are seizing the opportunities presented by mobile apps to acquire capabilities to do what they want to do and become who they would like to be, notwithstanding the restrictions and burden of caring for their children, spouses and other family members. However, the argument as to whether mobile app usage is helping women MBOs to become all they would like to be remains unanswered. This reflects the reality of unrealized capabilities and unfreedoms. While perfection cannot be assumed in the use of digital technologies, it is necessary to consider factors that are responsible for the unrealized capabilities and how to address them. Some of these factors may include the poor adaptation of mobile apps to a wide range of business situations. An example is the adaptation of WhatsApp as ecommerce solution for selling foods, and planning events. Other factors could stem 
from poor infrastructure, such as poor electricity supply, poor internet connectivity, and cyber security issues.

\section{$7 \quad$ Implications of findings}

In furthering the goal of this exploratory study which sought to understand how mobile app usage by MBOs in Lagos reflect gender gaps and freedom relative to Sen's capability approach, three main findings and their implications to ICT for development theories and practices are made.

First, the demography of MBOs seems to disprove a notion that women are usually at the receiving end of gender gaps or inequality, rather, the contrast between men and women regarding what they could do and achieve is a complex phenomenon that is difficult to generalize. Solving the problems of gender gaps and inequalities require problems solving approaches that consider the diversity of individuals and uniqueness of the community where they develop their individual capabilities to function.

Secondly, the descriptive statistics of MBOs suggests that women MBOs are more active in mobile apps usage than men MBOs. Women are leveraging on the use of technologies like mobile app to build their ability to function, to realise their dreams and experience sense of freedom. Moreover, Research findings suggest that policies driven by mobile app usage and focus on women MBOs will arguably produce better results because women MBOs seem to be more active in mobile apps usage. In addition, the understanding that at less than 20 years old, there are 3 women MBOs for every man MBO suggests the need for policies that will drive the development of entrepreneurial skills in men in early adulthood. Such policies should also consider the need to ensure female MBOs are kept in business as MBs and MBOs grows. Deliberate and strategic drive towards micro-business development in low income-country such as Nigeria promises an increased positive impact on the unemployment, poverty alleviation, and general well-being of a country with 200.96 million population, $60 \%$ are under 21 years old, $49.5 \%$ are female, and about $48 \%$ are female (less than 50 years). In addition, $25 \%$ are unemployed, and $48 \%$ are under-employed [10]. In the same vein, the tendency of women MBOs to use mobile apps more than their men counterparts could mean that testing beta-features of newly developed mobile apps with women MBO will likely provide better outcomes.

Thirdly, reflecting on this exploratory study from a normative viewpoint of capability approach, the problem of inequality (and ICT for development field) would benefit from more focused theoretical frameworks that explains associations between gender gaps and use of technology. This association would also consider how personal and community factors influence uptake of technology, and how the uptake enhances people's wellbeing, and their sense of freedoms or unfreedoms. This study attempted to conceptualize these relationships, and the results suggest that mobile apps are helping to close the gender and freedom gaps, although further research is needed. Nonetheless, it is identified that mobile apps could be instrumental in achieving the United Nations Sustainable and Development Goals (SDGs) goals that present roadmaps for addressing 
global challenges such as poverty, hunger, unemployment, inequality, peace and justice, environmental degradation and climate change [36]. Specifically, the $5^{\text {th }}$ goal that aims to promote gender equality and women empowerment. According to the Sustainable Development Goals Report [37], in 2015, medium-high and high-technology sectors accounted for $44.7 \%$ of total manufacturing value added globally. The value added reached $34.6 \%$ in developing economies, up from 21.5 per cent in 2005 . The implication is that if technologies like mobile apps can be made more widely accepted in businesses which have large populations of women who make up more than half of a country's population, economic growth can become a reality not only for the countries themselves, but for women as well.

\section{Conclusion}

Motivated by the drive to understand how MBOs use the mobile app along gender construct in low-income country context and business environment perceivably edged by male ideals, this research adopted an exploratory research approach and Amartya Sen's capability viewpoint. Data from 1,159 MBOs was analyzed and the results suggest that gender gaps in the context of MBOs in Lagos Nigeria are not one-sided in favor of men or women. Women are making use of mobile apps to more than men, women are seizing the opportunities presented by mobile apps to acquire capabilities to function, they adapt mobile apps to do what they want to do and become who they would like to be, notwithstanding the restrictions and responsibilities women experience in male dominated environments.

The study recommends that policies makers could explore the use of mobile apps to enhance the development of MBs, and the capabilities of women, and that the strategic use of ICTs like mobile apps could also contribute to the United Nations SDG 5 on gender equality and women empowerment in low income country contexts.

This study contributes to the literature in Information Systems (IS) and micro-business management in low-income country contexts, and also initiates debate regarding theoretical frameworks that could explain associations between gender gaps, technology uptakes and people's capability and sense of freedoms.

\subsection{Future research}

Future research could use confirmatory and explanatory approaches to investigate factors that influence how men and women MBOs use mobile apps in a low-income country context. This study was limited in its exploratory approach because it only considers data from Lagos only. Although Lagos is the economic hub of Nigeria, the data collected from Lagos may not entirely speak to micro-business realities in other states and regions in Nigeria. 


\section{References}

1. World Business Council for Sustainable Development (WBCSD): "The consequences of COVID-19 for the decade ahead Vision 2050 issue brief", (2020).

2. Magidimisha, H. H., Steven, G.: "Profiling South African gender inequality in informal self-employment," Journal of Gender Studies, vol. 24, no. 3, pp. 275-292, (2015).

3. Eniola, A., Entebang, H., Sakariyau, O.B.: "Small and medium scale business performance in Nigeria: Challenges faced from an intellectual capital perspective.," International Journal of Research Studies in Management, 4(1), vol. 4, no. 1, (2015).

4. Tom, E.Z., Glory, B., Alfred, U.J: " An Appraisal of Nigeria's Micro, Small and Medium Enterprises (MSMEs): Growth, Challenges, and Prospect.," International Journal of Small Business and Entrepreneurship Research, vol. 4, no. 4, pp. 1-15, (2016).

5. Siyanbola, T.O.: "Challenges of growth and development of manufacturing and Services SMEs in Nigeria.," in WEI International Academic, Harvard USA, (2015).

6. Ilegbinosa, I.A., Jumbo, E.: "Small and Medium Scale Enterprises and Economic Growth in Nigeria," International Journal of Business and Management, vol. 10, no. 3, p. 203-216, (2015).

7. Williams C., O: Patriarchy and the representation of women in Africa and Asia, $2^{\text {nd }}$ International Conference on 'Africa-Asia: A New Axis of Knowledge', Dar es Salaam, Tanzania, (2018).

8. Wakunuma, K, Siwale. J, Beck. R.: " Computing for social good: Supporting microfinance institutions in Zambia.," EJInfo Sys Dev Countries. , vol. 85, (2019).

9. Mbogo, M.: " The impact of Mobile Payments on the Success and Growth of MicroBusiness: The Case of Mpesa in Kenya," The Journal of Language, Technology and Entrepreneurship in Africa, vol. 2, no. 1, (2010).

10. Nigerian Bureau of Statistics, "Statistical Report on Women and Men in Nigeria," Nigerian Bureau of Statistics, Abuja, (2017).

11. Nigerian Bureau of Statistics: "Micro, small, and medium enterprises (MSME) national survey 2017 report, (2017).

12. Aker, J., Mbiti, I.:" Mobile Phones and Economic Development in Africa.," Journal of Economic Perspectives, vol. 24, no. 3, p. 207-232, (2010).

13. Wamboye, E.F, Nyaronga, P.J.: The Service Sector and Economic Development in Africa First., London and New York: Routledge, (2018).

14. Robeyns, I.: The Capability Approach in Practice. The Journal of Political Philosophy. Vol. 14, No. 3, p 351-376 (2006).

15. Robeyns, I.: Sen's capability approach and gender inequality: selecting relevant capabilities. Feminist Economics Vol. 9, p 61-92 (2003).

16. Sen, A.: Development as Freedom, Oxford: Oxford Press., (1999).

17. Robeyns, I.: "The Capability Approach," Stanford University, 3 October 2016. [Online]. Available: https://plato.stanford.edu/entries/capability-approach/. [Accessed 23 February 2020].

18. Robeyns, I.: "The Capability Approach - A Theoretical Survey," Journal of Human Development, vol. 6, no. 1, p. 94-114, (2005).

19. Doss, C., Meinzen-Dick, R., Quisumbing, A., Theis, S.: Women in agriculture: Four myths, Global Food Security vol.16, p. 69-74 (2018).

20. Nussabaum, M: Women and equality: The capabilities approach, International Labour Review Vol. 138, No. 3 (1999). 
21. Small and Medium Enterprise Development Agency of Nigeria (SMEDAN) \& Nigeria Bureau of Statistics (NBS), "SMEDAN and National Bureau of Statistics Collaborative Survey: Selected Findings," NBS, Abuja, (2013).

22. Bank of Industry, "MSME's Definition," Bank of Industry, [Online]. Available: http://www.boi.ng/smedefinition/. [Accessed 23 February 2020].

23. Ngwu, B.: "Small and medium enterprises (SMEs) in Nigeria: problems and prospects.," St. Clements University, 2005. [Online]. Available: http://stclements.edu/grad/gradonug.pdf.. [Accessed 20 February 2020].

24. Ashrafi, R., Murtaza, M.: "Usage and Effects of Information and Communication Technologies on Small and Medium-Sized Enterprises in Oman.," in International Conference on Information Resources Management (Conf-IRM), Ontario, (2008).

25. Bankole, F., Bankole, O.: " The effects of cultural dimension on ICT innovation: Empirical analysis of mobile phone services," Telematics and Informatics, vol. 34, no. 2, p. 490-505, (2017).

26. Young, D.: Improving the adoption of cloud computing by small and medium scale enterprises in Nigeria., Pretoria: The University of South Africa, (2015).

27. Cheng, Y., Tao, W., Gang, Y., Huaimin W., Ming W., Ming X.:"Personalized mobile application discovery," in 1st International Workshop on Crowd-based Software Development, Hong Kong, (2014).

28. Jun-Jie, H., Voon-Hsien, L., Keng-Boon, O., June W.: "What catalyses' mobile apps usage intention: an empirical analysis," Industrial Management \& Data Systems, vol. 115, no. 7, pp. 1269-1291, (2015).

29. Owoseni, A., Twinomurinzi, H.: " The dynamic capabilities of small and medium-scale enterprises using mobile apps in Lagos, Nigeria.," Electronic Journal of Information Systems in Developing Countries, p. pp.1-14., (2019).

30. Weber P., Geneste L.: "Exploring gender-related perceptions of SME success," International Journal of Gender and Entrepreneurship, vol. 6, no. 1, p. 15-27., (2014).

31. Sharafizad J.:" Women business owners' adoption of information and communication technology," Journal of Systems and Information Technology, , vol. 18, no. 4, p. 331$345,(2016)$

32. Françoise, O.-E., Gaëlle T. T.: "Female entrepreneurship and growth in Cameroon," African Journal of Economic and Management Studies, vol. 6, no. 1, p. 107-119, (2015).

33. Lagos State Government: "Lagos State Development Plan 2012-2025," Lagos State Government, Lagos, (2013).

34. Ministry of Economic Planning and Budget, "Overview of Lagos State, Nigeria.," Federal Government of Nigeria, Abuja, (2014).

35. George D., Mallery, M.: SPSS for Windows Step by Step: A Simple Guide and Reference, Boston.: Pearson, (2010).

36. United Nations: "The Sustainable Development Goals 2018," United Nations, New York, (2018).

37. United Nations: "Sustainable development goal 5: Achieve gender equality and empower all women and girls [Online]. Available: https://sustainabledevelopment.un.org/sdg5 [Accessed 20 February 2020]. 